\title{
WestVirginiaUniversity
}

THE RESEARCH REPOSITORY @ WVU

Graduate Theses, Dissertations, and Problem Reports

2011

\section{Evaluation of a Medication Reconciliation Practice Change in Primary Care}

Laura L. Danals

West Virginia University

Follow this and additional works at: https://researchrepository.wvu.edu/etd

\section{Recommended Citation}

Danals, Laura L., "Evaluation of a Medication Reconciliation Practice Change in Primary Care" (2011). Graduate Theses, Dissertations, and Problem Reports. 3033.

https://researchrepository.wvu.edu/etd/3033

This Dissertation is protected by copyright and/or related rights. It has been brought to you by the The Research Repository @ WVU with permission from the rights-holder(s). You are free to use this Dissertation in any way that is permitted by the copyright and related rights legislation that applies to your use. For other uses you must obtain permission from the rights-holder(s) directly, unless additional rights are indicated by a Creative Commons license in the record and/ or on the work itself. This Dissertation has been accepted for inclusion in WVU Graduate Theses, Dissertations, and Problem Reports collection by an authorized administrator of The Research Repository @ WVU.

For more information, please contact researchrepository@mail.wvu.edu. 
Evaluation of a Medication Reconciliation Practice Change in Primary Care

Laura L. Danals MSN, ANCS-BC

\author{
Doctoral Research Project submitted to the \\ School of Nursing at \\ West Virginia University \\ in partial fulfillment of the requirements \\ for the degree of
}

Doctor of Nursing Practice

Kari Sand-Jecklin EdD, MSN, RN, Chair

Janet Boeckman, DNP, RN

Lisa Hardman, DNP, BC-ADM, CDE

School of Nursing

Morgantown, West Virginia

2011

Keywords: Medication Reconciliation; Clinical Risk Management; Primary Care; Family

Practice; Outpatient Setting; Electronic Health Record; Medication Monitoring

Copyright 2011 Laura L. Danals 


\section{ABSTRACT \\ Evaluation of a Medication Reconciliation Practice Change in Primary Care \\ Laura L. Danals}

Statement of the Problem and Significance: Inaccuracies in patients' medication lists in primary care are safety concerns. Extensive research has been conducted on medication practices and patient safety within the hospital; however, the research for primary care is sparse.

Study Design: Lippitt's Change Theory was utilized as the theoretical framework. The project design was based on evidence derived from the 2008 The Joint Commission National Patient Safety Goals. The study was performed over a period of three months. Pre-intervention data was gathered and analyzed for the use of current electronic medication records. The healthcare team was educated on the electronic medication record system, and the importance of medication accuracy, listing of all pharmaceutical agents utilized by the patient, including over-the-counter agents, vitamins, herbals and home remedies. Post-implementation data was collected and analyzed two weeks post education to determine acceptance of the process change. Final postimplementation data was collected and analyzed at six weeks post implementation to evaluate adoption of the process change. Results were present to the team.

Sampling Methods: One hundred retrospective patient records were reviewed for each audit. Records were randomly selected from participating providers' encounters using the Research Randomizer tool. Mondays, Tuesdays and Thursdays, were used as audit days based on high patient volumes. Inclusion criteria included: English language, patients 18 years of age and older, one or more chronic disease diagnoses, and presence of one or more long-term maintenance medications. Fifteen patients were randomly selected from the pre and final postimplementation audits for a phone survey to establish baseline data and the healthcare teams' compliance with the process change. The healthcare team was surveyed for effectiveness of the educational intervention.

Results: There was significant evidence to support meeting medication reconciliation objectives. Patient reports of the telephone survey indicated $100 \%$ compliance with all criteria post practice change. There was a significant decrease in the number of medications listed and in the total number of active acute medications listed post practice change. Record audits indicated a significant increase in the number of over-the-counter, vitamins, herbals and home remedies and new over-the counter, vitamins, herbals and home remedies listed. A significant increase in compliance with checking the "Reviewed" box was also demonstrated.

Recommendations: Continue staff medication reconciliation behaviors. Re-audit the process at six months then annually, and develop a formal policy for the reconciliation practice at this facility. 


\section{Table of Contents}

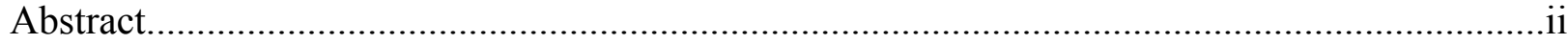

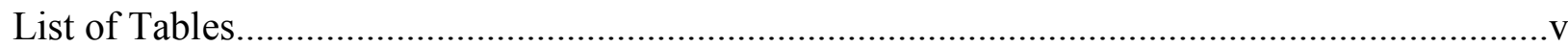

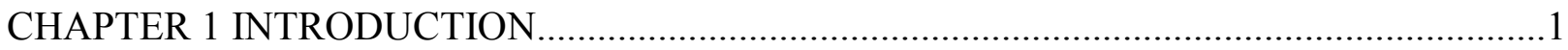

Background and Significance ......................................................................................1

Medication Safety and Errors............................................................................

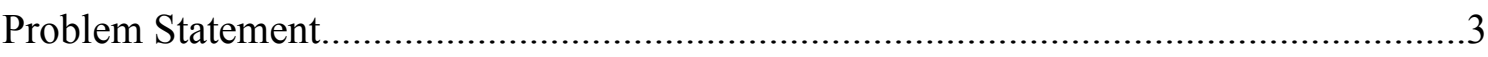

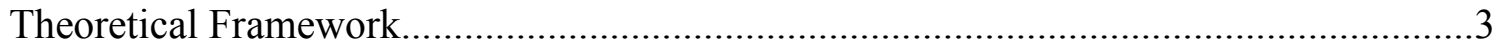

CHAPTER II REVIEW OF THE LITERATURE.............................................................

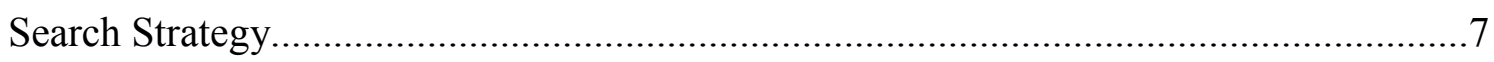

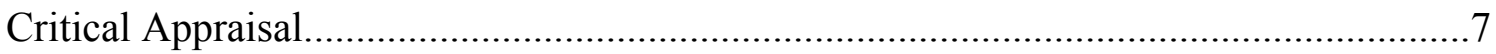

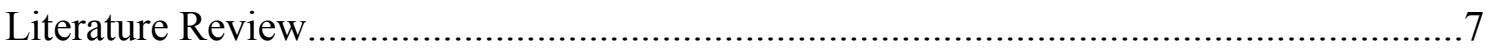

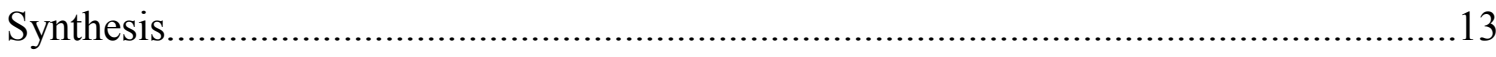

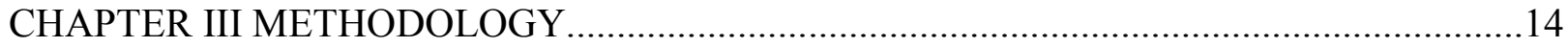

Medication Reconciliation Project Description.............................................................14

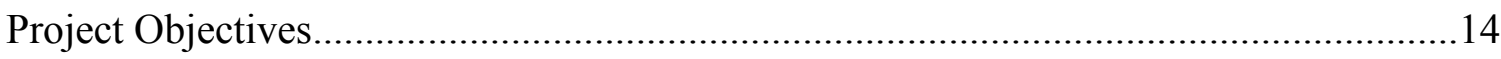

Evidence Based Project Design...................................................................................

Medication Reconciliation Practice Change.......................................................16

Project Timelines.................................................................................... 16

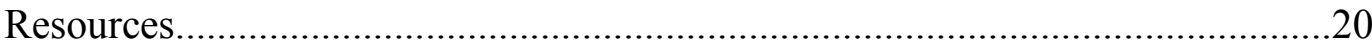

Financial Plan/Budget..........................................................................20

Statistical Analysis..................................................... 20

Human Participation Protection.......................................................................20

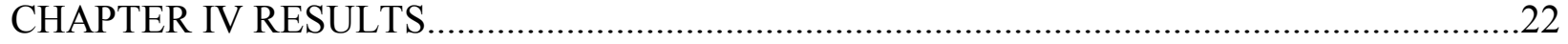

Medication Reconciliation Data Collection Results..................................22

Healthcare Member Survey Results............................................24

CHAPTER V SUMMARY, DISCUSSION, IMPLICATIONS.................................................26

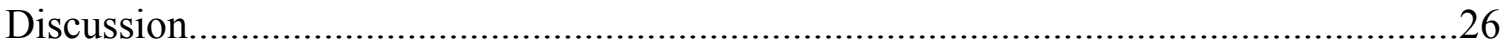

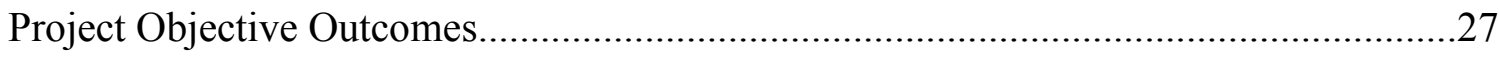

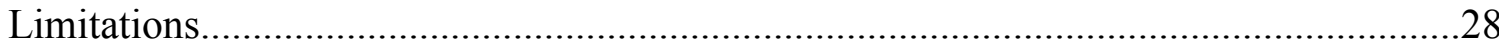




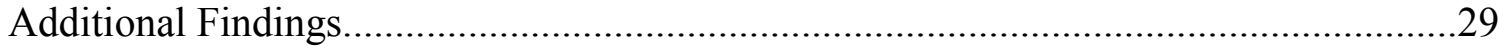

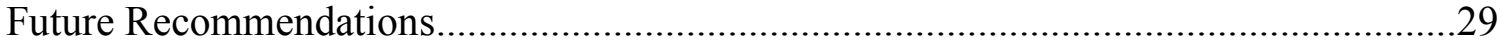

Relation of Practice Change Project to Personal Goals............................. 30

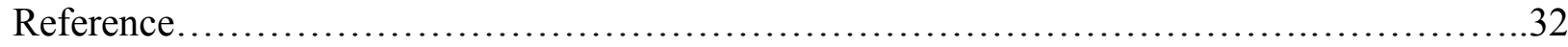

Appendix A Theoretical Framework Overview.......................................... 35

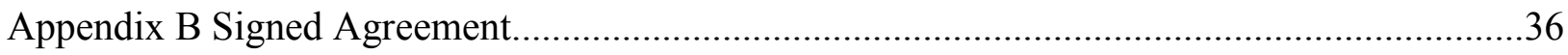

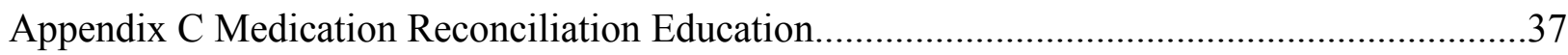

Appendix D Patient Educational Poster................................................40

Appendix E Medication Record Data Collection Form..................................41

Appendix F Telephone Survey Data Collection Tool....................................42

Appendix G Healthcare Member Evaluation Questionnaire................................................43

Appendix I Cover Letter................................................................. 44 


\section{List of Tables}

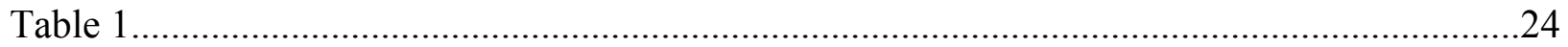




\section{Chapter One: Introduction}

\section{Background and Significance}

In 1820, The National Coordinating Council for Medication Error Reporting and Prevention (NCC MERP) was developed to set standards for medication safety. Working with the United States Pharmacopeia (USP) Institute for Safe Medication Practices (ISMP) [USPISMP], and the Medication Errors Reporting Program (MERP), the USP recognized that there were many reasons for medication inaccuracies and that no one institution was able to address this risk to patient safety. The USP has been engaged in medication error-reporting programs since 1991, when the MERP was developed in conjunction with the ISMP.

In 1995, the USP and the NCC MERP developed a standard definition for medication errors (NCC MERP, 2005). A medication error refers to any avoidable occurrence that has the potential to cause injury to the patient while under the management of the healthcare provider or consumer. These actions could be associated with the performance of the healthcare provider, the products themselves, or the structure and methods utilized by the organization. This process encompasses the development of the product along with its manufacturing and dispensing, the educational and ordering process related to the product, and the monitoring of its use (The National Coordinating Council for Mediation Error Reporting and Prevention [NCC MERP], 2005).

Medication Safety and Errors. Medication safety is an essential component of risk management for all healthcare systems. All patients are potentially vulnerable to medication errors. The potential for poor patient outcomes related to lack of strategies directed toward preventing or reducing the potential for medication errors to occur is significant (Tam at el., 2008; Rubin, George, \& Richardson, 2010; Bayoumi, Howard, Holbrook, \& Schabort, 2009; Thomsen, Winterstein, Sondergaard, Haughbolle, \& Melander, 2007; Leonhardt et al., 2008; Wet \& Bowie, 2009; Velo \& Minuz, 2009).

Patients' healthcare outcomes are directly impacted by medical errors and adverse events (Elder, Vonder Meulen, \& Cassedy, 2004). Medication errors occur in both general practice and hospital environments and have a direct impact on the patients' safety and quality of healthcare (Velo \& Minuz, 2009). Reported rates of medication inaccuracies vary throughout the literature depending on the measurements used for defining the events and the techniques used to obtain 
the data (Tam et al. 2008). In 1999, the Institute of Medicine (IOM) reported that 44,000 Americans die each year in hospitals as a result of medical errors (Institute of Medicine [IOM], 1999). Of concern is the lack of quality studies available that validate issues and outcomes related to medication inaccuracies in the primary care environment and compare these results with findings in the acute care setting (Tam at el., 2008; Rubin et al., 2010; Bayoumi et al., 2009; Thomsen et al., 2007; Leonhardt et al., 2008; Wet \& Bowie, 2009; Velo \& Minuz, 2009; Elder \& Dovey, 2002; Jones \& Moss, 2006; Elder et al., 2004).

Prescribing inaccuracies are medication-related factors contributing to poor patient health outcomes. Prescribing errors account for $70 \%$ of all medication errors, affecting about 4 in 1000 patient prescriptions (Velo \& Minuz, 2009). A study by Rubin and colleagues (2010) classified medication errors into six groupings: prescriptions, communication, appointments, equipment, clinical care, and other. These authors identified a total error rate of 75.6/1000 appointments. Computer input errors accounted for $13 \%$ of these errors, and $5 \%$ were clinical or medication errors (Rubin et al., 2010).

Medication mistakes in prescribing can occur for various reasons in the healthcare environment. MEDMARX is the largest United States Internet-accessible, risk free error reporting program that meets accreditation standards, state regulations, and audits compliance to National Patient Safety Goals (NPSG) devised for healthcare organizations to analytically gather, study, and account for medication errors. The MEDMARX system has identified approximately 50 causes of medication errors in their reporting system. The most commonly reported factor was distraction. The top ten causes of errors reported by MEDMARX in 2001 were: performance deficit; protocol not followed; transcription inaccurate/omitted; documentation; computer entry; knowledge deficit; communication; written order; drug distribution system; and handwriting illegible/unclear (Santell, Hicks, McMeekin, \& Cousins, 2003). A MEDMARX study by Santell and colleagues investigated 154,816 medication error reports submitted from 403 participating organizations and found that potential errors accounted for $9.7 \%$ of the reports, while actual errors equaled $91.3 \%$. Thirty six percent of these errors never reached the patients, and $97 \%$ of these errors did not cause harm; $83 \%$ of the harmful errors did not cause death, and only $0.47 \%$ or 19 harmful errors resulted in death (Santell et al., 2003). 
As of July, 2010, the final ruling was released including the Stage 1 Meaningful Use Objectives and Associated Measures for the Electronic Health Record Invective Program (Department of Health and Human Services, Centers for Medicare and Medicaid Services Medicare and Medicaid Programs, 2010). One of the core measures within the Meaningful Use ruling refers directly to the criteria for E-Prescribing which requires that a medication reconciliation process has occurred (Department of Health and Human Services, Centers for Medicare and Medicaid Services Medicare and Medicaid Programs, 2010). The E-Prescribing program began in 2010, and is one of financial incentive programs available to eligible professionals who met the electronic specifications relating to prescribing (Centers for Medicare and Medicaid Services [CMS], 2010).

\section{Problem Statement}

Inaccuracies in medication prescribing, including drug-drug interactions, drug allergies, disease-drug interactions, wrong doses, wrong drugs, and wrong patient, are major factors contributing to increased patient morbidity and mortality. Medication errors relating to the primary care environment include: omission, prescribing errors, wrong patient, time, dose, and route (NCC MERP, 2005). These medication mistakes are often preventable (Velo \& Minuz, 2009).

The influence of the medication reconciliation process on decreasing medical errors and adverse patient outcomes has been studied extensively in the hospital based population. However, there is a lack of evidence related the influence of the medication reconciliation process on medication errors and adverse events associated with outpatient provider-patient interactions (Elder et al., 2004).

\section{Theoretical Framework}

Change is inevitable. Technology in healthcare has changed drastically over the years. In today's fast paced health care environment providers need to have quick access to current, accurate, medical data to support the goal of providing patients with safe, effective, and accurate prescriptions to treat identified healthcare conditions. Before undertaking any significant practice changes or practice redesign, one must first assess the readiness for change of all providers (Holman \& Devane, 2000; Jones \& Moss, 2006; Lippitt, Watson \& Westley, 1958). It is essential to fully identify and assess all aspects of the change process, including all personnel 
potentially impacted, when implementing a system change within a practice setting. Failure to inform, involve, and adequately prepare the personnel affected by the change can have a negative impact on morale, create unnecessary and disruptive distractions in the work environment, and may ultimately adversely affect the timeline for implementation and overall success of the practice change (Holman \& Devane, 2000; Jones \& Moss, 2006; Lippitt et al., 1958).

The goal of this capstone project was to implement a planned change in the medication reconciliation process in an urban north central Ohio primary care practice. Lippitt's seven-step change theory was chosen to direct this process (refer to Appendix A for the Theoretical Framework Overview). Lippitt's theory focuses on several key concepts relating to systems: personalities, group interactions, facility culture and the society (Lippitt et al., 1958). Lippitt, et al. (1958) expanded Lewin's Three-Step Change Theory into a seven-step theory. The emphasis of Lippitt's theory was directed at the role and responsibilities of the change agent, verses the effects of change over time.

The first step in Lippitt's seven-steps is diagnosing the problem. In the practice change project reported here, this step began when the Physician/owner identified a need to adhere to the standards for an electronic prescription drug program under Title I of the Medicare Prescription Drug, Improvement, and Modernization Act of 2003 (MMA) (Centers for Medicare and Medicaid Services, 2005).

The second phase of Lippitt's theory refers to assessing the motivation for change. The Physician/owner's motivation for changing the previous electronic medical record (EMR) was based on the system's inefficacy to network outside of the facility, its inability to reconcile medication records, and the fact that the current system would not allow the facility to meet the proposed governmental standards for the medication reconciliation process or to qualify to for the government incentive programs for E-prescribing. The providers and healthcare team members agreed that the current system was inefficient, and concurred that the electronic system would need to be updated or replaced in order to improve the accuracy of the patient's medication record. Therefore, the Physician/owner chose to implement a new fully functioning electronic health record (EHR) in efforts to enhance medication safety resulting in improved patient outcomes. 
Clarifying the problem is the third step in the change process. The Primary Investigator (PI) identified that there were several inaccuracies in the providers' electronic medication lists while reconciling the EHR list with the patients' medication lists during patient encounters. The PI found: (a) the patients were not bringing in their medications or lists to office visits; (b) when verifying medications with the patients, numerous inaccuracies were found; (c) patients could not recall what medications they were currently taking; (d) acute medications (medications used to treat episodic conditions) remained listed as current medications beyond the dates prescribed; (e) evidence of over-the-counter (OTC) medications, vitamins, and herbals and home remedies were lacking in the EHR medication list, and; (f) patients were not given an updated medication list upon departure.

The fourth step of the process includes establishing the goals and alternative plans of action. The literature identifying best practice and standards relating to the medication reconciliation process and the impact on decreasing the likelihood of a medication error was utilized to develop the intervention for this practice change (CMS, 2005; Joint Commission on Accreditations of Healthcare Organizations [JCAHO], 2008; Bayoumi et al., 2009; Leonhardt et al., 2008).

The fifth stage of Lippitt's theory is identification of the change agent's role. This PI received approval to facilitate the educational processes and action plan for this practice change from the Physician/owner in efforts to enhance the practice of medication safety and meet the proposed governmental requirements for prescribing (refer to Appendix B for the Signed Agreement; Appendix C for the Medication Reconciliation Education; Appendix D for the Patient Educational Posters).

Implementing the use of the Medication Reconciliation Process is the sixth step of the change process. This process entailed a brief presentation of the medication reconciliation education handout followed by a demonstration of the medication process in the EHR system. The patient educational posters were secured to the back of every examination room for the patient to review while they were waiting on the providers (Appendix $\mathrm{C}$ for the Medication Reconciliation Education; Appendix D for the Patient Educational Posters).

The final step in the change process is the adoption of the medication reconciliation process. Record reviews and telephone surveys were performed to identify evidence of 
medication reconciliation and the healthcare team members behaviors of reminding the patients to bring their medications or list of medications to the office visit, reconciling all of their medications including OTCs, vitamins, herbals and home remedies in the EHR (refer to the Medication Record Data Collection Form in Appendix E; the Telephone Survey Data Collection Tool in Appendix F; the Healthcare Team Questionnaire in Appendix G). After implementation and evaluation of this practice change, the PI resumed normal APN duties within the practice (Lippitt et al., 1958).

Changing human behavior is a difficult and complex matter. Merely applying the suggested steps of any method, as if they were a recipe does not always create the outcomes that organizations desire (Holman \& Devane, 2000; Jones \& Moss, 2006; Lippitt et al., 1958). According to Geraci (1997), nurses are well equipped to serve as change agents due to their leadership qualities and knowledge base of methods needed to execute change. Lippitt's theory is supportive in illustrating how to direct a designed process change (Geraci, 1997). Therefore, it was useful to embrace Lippitt's change theory as the model for adopting a practice change associated with the medication review and prescribing methods utilized in this primary care office (refer to Appendix A for the Theoretical Framework Overview). 


\section{Chapter Two: Review of the Literature}

\section{Search Strategies}

The focused literature search strategy for this project included CINAHL, MEDLINE, EbscoHost, PubMed, Health Source: Nursing/Academic Edition, Academic Search Complete, and International Pharmaceutical Abstract. No limits were set on the years, language or country, but the search was limited to full text. Using the keywords medication errors in primary care, clinical information systems, and electronic medical/health records the initial search yielded 1229 hits. The search was narrowed by the inclusion of peer reviewed manuscripts and years of 2005 to present, resulting in a total of 207 hits. Abstracts were reviewed for inclusion criteria of medication reconciliation processes in an ambulatory care setting, from which thirty relevant articles were selected for review. An additional search of The Joint Commission data bank resulted in three additional articles, and snowballing revealed two additional articles.

\section{Critical Appraisal}

A total of ten studies were selected for detailed appraisal. Four systematic reviews (SRs) (Boayoumi et al., 2009; Chaudhry et al., 2006; Thomsen at el., 2007; Elder \& Dovey, 2002), three randomized control trials (RCTs) (Tam et al., 2008; Santell et al., 2003; Wet \& Bowie, 2009), and one quasi-experimental design study (Leonhardt et al., 2008) were chosen for analysis. Each was individually appraised for internal validity, study description, and overall assessment of the study using the Scottish Intercollegiate Guidelines Network (SIGN) Systematic Reviews and Meta-analyses form, and Randomized Controlled Trial form (SIGN, 2007). The Larrabee (2009) Literature Review Worksheet was utilized to validate findings from the two qualitative study (Hesselgreaves, Lough, \& Power, 2009; Elder at el., 2004).

\section{Literature Review}

A systematic review was conducted by Bayoumi and colleagues (2009) to investigate differences between the patients' and the healthcare provider's medication lists at baseline, then again after performing medication reconciliation at each clinic visit. Two before and after studies investigated 275 adult patients and found prescription medication differences were decreased from $88.5 \%$ at baseline to $49.1 \%$ post intervention (OR $0.13,95 \%$ CI 0.07 to 0.21 ) and the number of medication lists with inconsistencies was decreased from $88.9 \%$ at baseline to $66 \%$ post intervention $(\mathrm{p}=0.005)$, which was statistically significant. The second study noted no 
significant difference in discrepancies from baseline at $40.4 \%$ to post intervention at $45.4 \%$ (OR $1.23,95 \% \mathrm{CI} 0.93$ to 1.62 ), and quantity of medication list inconsistencies increased from $76.3 \%$ at baseline to $82 \%$ at post intervention $(\mathrm{p}=0.442)$ which the authors attributed to heterogeneity of data (Bayoumi et al., 2009).

Strengths associated with this study were: study design and use of two independent reviewers. Limitations were identified as: limited evidence of studied intervention, decreased validity of studies due to design issues, and heterogeneity of studies which prevented a metaanalysis.

Chaudhry and colleagues (2006) performed a systematic review to determine the impact that health information technology (HIT) had on the quality, efficiency, and cost of care. Effects on quality were recognized as a decrease in medications errors. Two studies of computerized provider order entry (CPOE) demonstrated a decline in adverse drug occurrences (from 28 to 4 events, $0.9 \%$ to $0.03 \%$ of total medications). The principle end point for adverse drug occurrences was non-intercepted serious medication errors which showed a $55 \%$ qualified reduction. A follow-up study conducted by the same researchers investigated the long-term effects of the system by evaluating adverse occurrences not prevented by CPOE, and found an $86 \%$ qualified reduction in non-intercepted serious medication errors (Chaudhry et al., 2006).

Strengths associated with this study include: the design, data review conducted by two independent reviewers, and a meta-analysis. Limitations identified include: quantity of quantitative studies, various HIT systems, and, heterogeneity in reporting HITs capabilities.

A systematic review of twenty nine studies conducted by Thomsen and colleagues (2007) sought to explain the characteristics of preventable adverse drug events (pADEs) in ambulatory settings. The authors found: median adverse drug event (ADE) was 14.9 per 1000 personmonths and the pADE rate was 5.6 per 1000 person-months. The median rate of ADEs resulting in hospitalization was 0.45 per 1000 person-months and pADEs was 4.5 per 1000 personmonths. The median ADE preventability incidence was $21 \%$. The use of inappropriate medications had the highest frequency of pADEs at $42.7 \%$ and insufficient supervision of pADEs resulting in hospitalization was $45.4 \%$ among the ambulatory studies (Thomsen et al., 2007). 
Strengths related to this study include the design, inclusion criteria, sample size, and generalizability. Limitations noted were: variances in reporting data, variances in definitions of terms, heterogeneous nature of data not permitting calculation of a meta-analysis, and lack of research studies for ambulatory settings.

Elder and Dovey (2002) conducted a systematic review to recognize identify and classify practice errors and avoidable adverse events in primary care. As a result of the different analyses used to examine the seven studies, an appraisal of quality and quantitative evaluation of data were not achievable. After synthesis of the results, a working classification system of avoidable adverse events and practice errors was designed. The classification system was proven to be valid and reliable through literature review, and is to be used to assist providers in understanding how practice errors and avoidable adverse events occur in primary care (Elder \& Dovey, 2002).

The strengths of this study were that the design was a systematic review conducted by two independent reviewers with agreed upon inclusion criteria. Limitations related to this study include: heterogeneity in reporting of data, small sample size, and lack of published studies available focusing on classifying practice errors and avoidable adverse events in primary care.

Tam and colleagues (2008) conducted a randomized controlled study in four practices over a period of two months to evaluate the limitations of voluntary reporting, chart audits and patient questionnaires in identifying medication errors in primary care. These authors also investigated the errors for severity and avoidability, the medication groups, and contributing factors involved in an effort to develop preventive strategies. A total of 73,117 prescriptions averaging 2.67 medications per prescription resulted in: voluntary reporting of 250 errors $(0.34 \%$ prescriptions: $95 \%$ confidence interval, $0.3-0.38 \%$ ), and 132 avoidable adverse events noted ( $0.18 \%$ prescriptions; $95 \%$ confidence interval, $0.15-0.21 \%$ ). Chart audits of 2056 records identified four errors ( $0.07 \%$ prescriptions; $95 \%$ confidence interval, $0-0.14 \%)$ and 107 avoidable adverse events (1.96\% prescriptions; $95 \%$ confidence interval, $1.59-2.33 \%)$. Results from 600 patient telephone questionnaires, totaling 1438 prescriptions, identified six errors ( $0.42 \%$ prescriptions; $95 \%$ confidence interval, $0.09-0.75 \%$ ) and 15 avoidable adverse events (1.04\% prescriptions; $95 \%$ confidence interval,0.54-1.56\%). Chi-square statistics demonstrated that the chart audits provided the best results for identifying errors in all three categories $(\mathrm{p}<0.0001)$; patient questionnaires produced intermediate results $(\mathrm{p}<0.0001)$; and voluntary 
reporting demonstrated the lowest results $(\mathrm{p}<0.0001)$. Of the 260 errors identified, 252 were prescription errors, five were related to dispensing, and three were related to patient factors (Tam et al., 2008).

The strengths related to this study include: the design was a randomized control study, three techniques were used to gather the data, and appropriate statistical analyses were used to appraise the data. Limitations of this study include: physicians' knowledge and training relating to preset criteria for using classification tables and time constraints required for the training and meeting times of the physicians. The telephone survey study was conducted over a two month time period, which had the potential for decreased recall of the drug error on the behalf of the patients. The limited numbers of published studies available for review exploring the prevalence of medication events and errors in primary care was also identified as a limitation.

A randomized controlled study conducted by Santell and colleagues (2003) utilizing the MEDMARX reporting system investigated 154,816 medication errors submitted from 403 participating organizations. The results reflect all participating organizations due to the study design, but for the purpose of this review the classifications will only reflect those errors that have the potential to occur in the primary care environment. These would include: potential errors (9.7\%), actual errors (91.3\%), intercepted errors (36\%), errors resulting in no-harm (97\%), harmful errors not resulting in death $(83 \%)$ and errors resulting in death $(0.47 \%)$. Using an 11item medication error list, the cause of errors was reported as: improper doses (20.8\%), prescribing errors $(12.1 \%)$, wrong patient $(5.2 \%)$, wrong form (1.8\%), and wrong route $(1.8 \%)$. Investigation of where the errors originated found: prescribing (15\%), documenting (26\%), and monitoring (1\%). Contributing factors associated with errors were found to be: distraction (49\%), increased workload (22.9\%), inexperience (17.3\%), lack of staffing (12.5\%), emergency circumstances (3.4\%), lack of 24-hour pharmacy (2.9\%), lack of access to patient records (1.9\%), and lighting $(0.7 \%)$ (Santell et al., 2003).

Strengths related to this study include the design was a randomized controlled study of MEDMARX, which is the largest United States internet-accessible, risk free, error reporting program that meets accreditation standards, state regulations, and audits compliance to National Patient Safety Goals (NPSG) devised for healthcare organization. Limitations of the study were found to be that data is submitted in a descriptive form, lack of comparative analysis of the data, 
voluntary reporting, and limitations relating to participants who were primarily hospital organizations.

A focused review was conducted of a randomized controlled study that used patient's electronic records to test and validate a global trigger tool designed to investigate the number, type and severity of errors in primary care. A trigger refers to identified flags, alerts, or prompts within the patient's electronic medication record that alerts the healthcare team to potential adverse occurrences and potential medication errors (Wet \& Bowie, 2009). From a review of 500 records, 730 triggers were recognized in which $9.4 \%$ led to patient harm, in $3.4 \%$ no harm to the patient occurred, and $42 \%$ of the errors were identified as preventable. The authors identified that $9 \%$ of the patients experienced some degree of harm. They also determined that the number of identified errors increased with age greater than 65 years (59\%) and particularly with patients 75 years and older (36\%), due to the increased number of prescribed medications (Wet \& Bowie, 2009).

Strengths related to this study are the design, inter-rater reliability, trigger methods with proven reliability, and large sample size. Limitations found in this study are identified as: lack of generalizability, potential for bias, and the limited amount of published studies that were available for review relating to the prevalence of medication events and errors focusing on primary care.

Leonhardt and colleagues conducted a large quasi-experimental study to determine the effect of a community based education program focusing on encouraging patients and healthcare providers to develop a partnership to improve the accuracy of the provider's medication lists. This study was conducted over a period of two years. The intervention group consisted of patients 55 years of age and older whose care was provided by one of 23 primary care providers located in five outpatient clinics in Wisconsin. The control group was made up of 363 primary care providers from 68 other outpatient clinics in Wisconsin. The authors found in the five intervention sites that the total baseline rate of accurate medication lists was $55 \%$ and it was $63 \%$ in the control sites, which reflected a significantly higher percentage at baseline $(\mathrm{p}<0.001$, Fishers exact test). The post intervention rate of accurate medications for the intervention sites was $72 \%$ and for the control sites it was $56 \%$, indicating a significant difference $(\mathrm{p}<0.001)$. The 
increased rate of medication list accuracy at the intervention sites as compared to the control sites was significant from baseline to post intervention $(\mathrm{p}=0.034)$ (Leonhardt et al., 2008).

Strengths identified within this study were the: design, length of study, and large sample size. Limitations identified within this study were: limited generalizability, narrow sample demographics, lack of data relating to the medication route, dose, frequency, use of over-thecounter drugs, herbal remedies, and the issue that no inter-rater reliability was established.

A qualitative study was conducted by Elder and colleagues (2004) in which the investigators had physicians identify errors occurring during an office visit and evaluate their interpretation of these errors. The authors identified that the impact of medical errors in primary care is less apparent than the hospital environment. A classification system for errors that had previously been designed for the hospital setting was adapted to reflect errors that were likely to occur at an office visit. Fifteen family practice physicians completed tools for 352 patient visits in which 117 errors were identified for 83 patient visits (23.6\%). The most frequently occurring errors were office administration errors at $16.5 \%$; physician errors at $8.0 \%$; patient communication errors at 4.5\%; and, avoidable adverse events at 4.3\%. Questions relating to harm were addressed for 76 out of the 83 patient visits in which an error was indicated. The investigators estimated that harm had occurred in 18 patients $(23.7 \%)$, potential harm had occurred in 53 patients (69.7\%), and, that the harm that had occurred was identified as minor. The physicians in the seven practices identified that $25 \%$ of their patient visits identified errors (Elder et al., 2004).

Strengths identified were: descriptions and classification of errors, and the validity of the classification tool. Limitations noted were: limited generalizability, lack of electronic medical records, errors were only tracked during the visits, physicians feared litigation, and a limited number of published studies relating to medication errors in primary were available for review.

Hesselgreaves and colleagues (2009) conducted a qualitative study to investigate the receptionists' perceptions of medication errors in general practice. The authors identified four reasons why the receptionists thought that errors occur: trust in the provider, patient communications, workload, and hospital communications (Hesselgreaves et al., 2009). Strengths related to this study are: signed consents by the participants, voluntary taped and video recorded interviews and reviewed by the researcher using an iterative process in two phases. 
Limitations relating to this study are: small sample consisting of three participants and limited generalizability due all participants being female.

\section{Synthesis}

Evidence found by a critical review of current studies based on data relating to the hospital environment demonstrate that there is a benefit to conducting a medication reconciliation process in primary care (Bayoumi et al., 2009). Chaudhry and colleagues (2006) investigated improving quality of care through clinical monitoring related to frequency of events, while Elder and Dovey (2002) designed a classification system of avoidable adverse events for practice errors. Wet and colleagues (2009) strove to test and validate a global trigger tool designed to investigate the number, type and severity of errors in primary care, while Elder and colleagues (2004) and Hesselgreaves and colleagues gathered qualitative data on potential errors occurring during an office visit. Thomsen and colleagues sought to explain the characteristics associated with medications errors, while studies by Bayoumi and colleagues (2009) and Leonhardt and colleagues (2008) examined the differences between the patients and the providers medication lists. Studies conducted by Tam and colleagues and Santell and colleagues investigated the occurrence of potential and actual errors as well as where they originated.

Through the appraisal process several key themes emerged which made it difficult to combine and analyze the findings due to the heterogeneous results. These include: uses of numerous definitions, varying classification systems, lack of reporting systems/monitoring, identified contributing factors, lack of generalizability, varying sample size and lack of robust studies. All studies reviewed identified the need for future research relating the impact of medication reconciliation on medication errors in primary care. 


\section{Chapter Three: Methodology}

\section{Medication Reconciliation Project Description}

The clinic site for this practice change project does not have formal organizational goals, value statements, or a mission statement. What was of most importance to this facility was to provide safe, cost-effective, holistic medical care to the patients that it serves. The primary goal of this project was to evaluate the use of the medication reconciliation process in the currently used EHR within this facility and to improve the accuracy of medication records contained in the EHR. The plan was to improve the safety of medication practices by adopting the medication reconciliation process as a standard of practice for the facility.

\section{Project Objectives}

The capstone project objective are in the SMART format; Specific, Measurable, ActionOriented, Realistic, and Timed. The objectives were created by considering all primary and secondary audiences. Evaluations of these objectives are addressed in the evaluation portion of this paper. For this project, there were three main objectives: (a) the healthcare team at the capstone facility will remind patients to bring in all of the pharmacology agents they are currently taking/using at every encounter; (b) the healthcare team at the capstone facility will demonstrate patient medication reconciliation as evidenced by entry of current patient medications, entering "Stop Date" for acute medications, reconciling more than one drug from the same class, and ; (c) the healthcare team at the capstone facility will add the patients regularly used OTCs, vitamins, herbals and home remedies into the electronic medication record and check the "Reviewed" box for at least $75 \%$ of the patient encounters. The threshold of $75 \%$ compliance was selected as the initial goal to demonstrate adoption of the process change, with the long term goal set at $100 \%$. This threshold is based on a poster abstract by Web and colleagues which identified that physicians achieved 76 to $80 \%$ reconciliation of medications, after a practice change (Webb et al., 2010).

\section{Evidence Based Project Design}

Electronic Prescribing (E-Prescribing) systems have the potential to enhance accuracy by electronically transmitting prescriptions between prescribers, pharmacies, and health plans. By adopting an E-Prescribing system, health care providers can reduce prescribing inaccuracies, adhere to guidelines, and monitor patients' outcomes of treatment strategies (Bell \& Friedman, 
2005). Information technology has the ability to decrease the rate of medication errors by providing tools that improve communication, aid with calculations, assist with monitoring compliance, execute checks in real time, and provide real-time clinical decision support networks (Bates \& Gawande, 2003). In efforts to bring medicine up to date with the advances in technology, the CMS spearheaded the development of criteria know as Meaningful Use (CMS, 2005).

The CMS (2005) Medicare Program; E-Prescribing and the Prescription Drug Program, proposed standards for an electronic prescription drug program under Title I of the Medicare Prescription Drug, Improvement, and Modernization Act of 2003 (MMA). These standards served as the first set of uniform foundation standards for an E-Prescription drug program in the MMA, and signify the initial stride towards adopting final foundation standards within the MMA objectives of patient safety, quality of care, and efficiencies and cost savings in the delivery of healthcare (CMS, 2005). As of July 2010, the final ruling was released including the Stage 1 Meaningful Use Objectives and Associated Measures for the Electronic Health Record Invective Program. There are three main components of Meaningful Use (a) use of a certified electronic health record (EHR) in a significant way - E-Prescribing, (b) electronically exchange health information to improve quality of care and, (c) submit clinical quality measures electronically (Department of Health and Human Services, Centers for Medicare and Medicaid Services Medicare and Medicaid Programs, 2010).

Because of the lack published standards when this project was initiated, the medication reconciliation in primary care was designed and implemented into practice based on evidence derived from the 2008 The Joint Commission National Patient Safety Goals (NPSG), even though The Joint Commission goals are not widely used in the primary care environment. The NPSGs that apply to the medication reconciliation process in primary care are 08.01 .01 which entails comparing the patient's current pharmacological agents to the provider's medications list and including newly prescribed medications; 08.03 .01 entails providing a written listing of all the pharmacological agents the patient is to be taking/using at departure, and; 08.04.01 refers to reconciliation of medications used for short durations (Joint Commission, 2008).

Reconciliation is the practice of comparing the patients' medications or list of medications with the medications that the organization has recorded, as identified in 
NPSG.08.01.01. The reason for this comparison is to decrease the likelihood of transcription and omission errors, duplication of medications, drug-drug interactions, and drug-disease interactions. It is up to the organization to identify who is qualified to perform the medication reconciliation process (Joint Commission, 2008).

The departure or discharge reconciliation list NPSG 08.03.01, requires that a written copy of the medication reconciliation list be provided to the patient upon departure (post-office visit). Medications used for short term are discussed in NPSG 08.04.01. Reconciliation of patient's medications, vitamins, and herbal remedies is an important safety measure that would assist in the reduction of morbidity and mortality related to medication errors in the prescribing process (Joint Commission, 2008).

\section{Medication Reconciliation Practice Change}

The overall goal of this capstone project was to improve medication safety related to the prescribing practices within this primary care practice in urban north central Ohio by utilizing an electronic medication reconciliation process. Reconciliation of the patient's medications, OTCs, vitamins, herbals and home remedies is an important safety measure that could assist in the reduction of morbidity and mortality related to medication mistakes in the prescribing process (Joint Commission, 2008).

This project was performed over a time period of three months. One hundred retrospective patient records were reviewed through pre and post-implementation audits. Records were randomly selected from the list of participating provider's encounters using the Research Randomizer tool. The providers at this facility are comprised of one physician and three APNs; the PI was excluded from the study leaving two APNs for the review. The days chosen for the review were Mondays, Tuesdays and Thursdays, based on identification of high patient volume days. This facility provides care to approximately 40 to 50 patients daily. Inclusion criteria included patients 18 years of age and older, English language speaking, one or more chronic disease diagnoses, and one or more long-term maintenance medications. A listing of one or more chronic disease diagnoses was used in efforts to capture the likelihood of patients being on one or more long-term maintenance medications, meaning medications prescribed for 30 days or longer with one or more refills. Once selected for the review, each patient's medication record was assessed for evidence of the reconciliation process indicated by: 
"Reviewed patient's new medication history" being present on the patients electronic medication record; presence of OTCs, vitamins, herbals and home remedies; absence of active acute medications past completion date; and lack of more than one active medication from the same drug class (refer to Appendix E for Medication Record Data Collection Form). Each audit continued until reaching the total of 100 records. Patient medical record numbers were used as the identifiers and kept separate from the data collection in efforts to maintain patient confidentiality. All data collected were stored in a private office used only by the providers in a locked file cabinet within the office in the facility.

The reconciliation process included the comparison of all of the patient's medications, OTCs, vitamins, herbals and home remedies or an entire listing to the provider's lists. A preintervention telephone survey was utilized to assess if the patients were informed by the receptionist during their appointment reminder call to bring all of the medications, OTCs, vitamins, herbals and home remedies they are currently taking/using with them to their visit. Five patients seen on each day (Monday, Tuesday, and Thursdays) were selected from those whose electronic medication records were previously monitored for reconciliation, using a mix of the providers. Every attempt was utilized by the PI to contact a total of 15 patients to complete the pre-telephone survey within two days after the patients office visit. If the patient was unable to be contacted after three attempts, another patient from the same provider visiting on the same day was contacted. All telephone calls were completed in a private room used only be the providers in the facility, and the data was stored in a locked file cabinet within this office in the facility.

The telephone survey consisted of four questions; (a) Were you instructed during your appointment reminder call to bring in all of your medications or list of medications, including OTCs, vitamins, herbals and home remedies you are currently taking/using? (Y or N), (b) Did you bring in all of your medications or medication list, including OTCs, vitamins, herbals and home remedies you are currently taking/using? (Y or N), (c) Did one of the healthcare team members review your medications/list, including OTC, vitamins, herbals and home remedies with you, making any needed changes in the computer? ( $\mathrm{Y}$ or $\mathrm{N}$ ) and, (d) Where you given a printed medication list upon your departure? ( $\mathrm{Y}$ or N) (refer to Appendix F for the Telephone Survey Tool). 
After the baseline data had been collected, the Medication Reconciliation education was presented to the healthcare team at the facility, stressing the importance of the medication reconciliation process, followed by a demonstration on the electronic system on how to reconcile the patients' medication list. This included entering the complete list of all pharmacologic agents the patient was taking/using including medications, OTCs, vitamins, herbals and home remedies, along with entering stop dates in the "Stop Date" box for pharmacological agents that were no longer used, or changes in dosage or frequency of a medication. The providers were then instructed to verify that the reconciliation occurred by assessing the patient's electronic medication record for listings of OTCs, vitamins, herbals and home remedies, "Stop Date" for all acute medications past completion date, only one active medication from the same drug class, and reviewing all potential interactions within the patients medication record. After the providers reconciled the EHR with the list of medications, OTCs, vitamins, herbals and home remedies that patient reported taking, they were to check the "Reviewed" box located in the medication record. The healthcare team was educated on the purpose of reviewing of the patient's current medications for errors, omissions, interactions, and contraindications as a method of improving medication safety within this facility. The healthcare team was instructed on the location of the "Reviewed patient's new medication history" in the record, indicating that the reconciliation process had been completed.

The handout provided also identified each team member's responsibilities in this process, in efforts to decrease confusion during the implementation of the practice change. The change process started with the receptionist instructing every patient at all visits to bring in or supply a complete list of all their medications, OTCs, vitamins, herbals and home remedies they are currently taking/using. In this facility, the physician has deemed that the medical assistants are the personnel responsible for entering and comparing all of the patient's pharmacological agents/list to the provider's current list, making changes as necessary and entering "Stop Date". The providers were responsible for verifying that the medication reconciliation took place by looking for the evidence of OTCs, vitamins, herbals and home remedies; lack of acute medications listed as active past the completion date; and, lack of more than one medication from the same drug class on the patient's medication record. Once the providers had completed the reconciliation process they checked the "Reviewed" box, and printed the medication record 
at the end of the encounter. The receptionist then presented the printed copy to the patient during departure (refer to Appendix C for Medication Reconciliation Education). Educational posters on $81 / 2$ by 11 card stock paper using a sixth grade reading level were placed on the back of each examination room door to stress the importance of this process change to the patients (refer to Appendix D for Educational Posters). The reading level of the poster was assessed using the Flesch-Kincaid method on Microsoft Word.

Following the educational intervention and implementation of this practice change, two retrospective post-implementation record audits were conducted at weeks two and six. The short term interval was used to identify any potential problems/issues with the reconciliation process, and the six week interval identified the degree of adoption of the new behavior. As with the preintervention audit, records were randomly selected from the list of participating providers encounters using the Research Randomizer tool. Each audit continued until a total of 100 records were reviewed.

The healthcare team was surveyed by the PI after completion of the first postimplementation audit for their evaluation of the medication reconciliation process change. The open-ended questions used for this process were: (a) Overall, what are your thoughts about the medication reconciliation process, including both phone reminders for patients to bring in their medications or a list of medications, and the reconciliation during the office visit (respondent write in response)? (b) What problems or barriers have you identified with this process? (c) What benefits have you found related to the process? (d) Is there anything that you would suggest to improve this process? Adjustments relating to the project based on the healthcare teams input and analysis of the audit data were made at that time (refer to Appendix G for the Healthcare Member Evaluation Questionnaire).

The final post-implementation data were collected at week six using the same methods as in the previous collections until an additional 100 records had been randomly reviewed. The preintervention audit data were then compared to the post-implementation audit data to evaluate the project in relation to meeting the identified objectives.

The post-implementation telephone survey data were gathered using the same methods as in the pre-intervention until a total of 15 patients had been contacted. The post telephone survey data were utilized to assess the healthcare teams' adoption of the behaviors to remind the patients 
to bring their medications or list of medications to the office visit, performing the medication reconciliation in the EHR, and provision of a reconciled list to the patient at the conclusion of the office visit.

\section{Resources}

Key resources for this project were the healthcare team at the facility, capstone committee members, and statistical support from the statistician at WVU. The tools used to gather data, educate the healthcare team and patient educational posters were developed by the PI as part of this capstone project. Overall cost associated with this project total $\$ 56.00$, office space and computers were provided by the facility.

\section{Statistical Analysis}

Descriptive analysis was conducted on all data collected from all three record audits and two telephone surveys. Chi-Square analysis was used to compare the differences in responses between the pre-intervention and the final post-implementation telephone survey. Chi-Square analysis was used to compare the statistical difference between pre-intervention and the final post-implementation data for performing the medication reconciliation by entering "Stop Date" for acute medications, and reconciling more than one drug from the same class and checking the "Reviewed" box. The Kruskel-Wallace test for non-parametric data was used to analyze the differences between the pre and post implementation listing of regularly used OTCs, vitamins, herbals and home remedies and number of medications listed and the number of medications past completion date. Goal attainment was set at a 50\% increase from baseline data and/or a threshold of $75 \%$ overall compliance for the reconciliation of patients medications within the EHR and absences of active acute medications past completion date. All levels of significance were set at $p=.05$. Data were analyzed by using the Statistical Package for Social Science [SPSS] version 18.

\section{Human Participation Protection}

Two affiliation agreements were obtained prior to the implementation of this project. A signed agreement was first obtained from the Physician/owner of the facility (refer to Appendix $B$ for site agreement). The second approval was obtained from the WVU Board of Governors on behalf of the WVU School of Nursing and; approval of the Institutional Review Board (IRB) at WVU which deemed this project was exempt from causing harm to humans. A cover letter was 
read to all the patients contacted to complete the telephone survey prior to asking the survey questions (refer to Appendix I for the Cover Letter). 


\section{Chapter Four: Results}

\section{Medication Reconciliation Data Collection Results}

One hundred electronic medication records were reviewed in the baseline data audit, and 100 charts were reviewed in both two-week and six week post-implementation data audits. Of these reviews the mean age of the patients was 63.01 at baseline, 61.48 at the first postimplementation review, and 62.84 at the final post-implementation review. There was no significant difference in age between the three audits. The mean number of chronic diagnosis listed in the EHR for the baseline audit was 4.08, as compared to 4.12 for the two week postimplementation audit, and 4.49 for the six week post-implementation audit. There was no significant difference in the number of chronic diagnosis between the three audits.

Of the indicators for the medication reconciliation, the mean number of medications listed on the chart was 7.99 for the baseline audit, 5.85 for the two week post-implementation, and 6.99 for the six week post-implementation. Kruskal-Wallace analysis indicated a significant difference in these results with Chi-Square $(\mathrm{df}=2), 8.96, \mathrm{p}=.01$. The mean number of new acute medications on the chart was .46 at baseline, .53 at the two week follow-up and .52 at the six week follow-up. There was no significant difference between these results. There was a mean of .67 medications listed that were past the completion date at baseline review, in comparison with .19 at the two week post-implementation audit and .04 at the six week postimplementation audit. Kruskal-Wallace analysis indicated a significant difference between these results: Chi-Square $(\mathrm{df}=2)=30.6, \mathrm{p}=.000$.

The mean number of OTC medications, vitamins, herbals and home remedies listed on the chart at the baseline audit was .33, in contrast with 1.55 in the two week follow-up audit and 2.34 at the six week follow-up. Kruskal-Wallace analysis indicated a significant difference between these results: Chi-Square $(\mathrm{df}=2)=60.70, \mathrm{p}=.000$. The mean number of new OTC medications, vitamins, herbals and home remedies listed on the chart at the baseline audit was .03. The mean number of newly listed products at two week follow-up audit was 1.13 and at the six week follow-up audit was .96. Kruskal-Wallace analysis indicated a significant difference between these results: Chi-Square $(\mathrm{df}=2)=48.68, \mathrm{p}=.000$. Additional data was gathered during the week six post-implementation audit in efforts to capture patients who had a previous clinic encounter after implementing of the new process, but prior to their encounter during the 
final data collection date. It was found that a total of 120 OTCs, vitamins, herbals and home remedies had been added after the implementation date for the last 100 records reviewed.

In the baseline chart audit there were two active medications within the same drug class in $27 \%$ of cases. In the two week post-implementation, $25 \%$ of cases had two active medications in the same drug class, in comparison with $6 \%$ in the six week post implementation audit. ChiSquare analysis demonstrated a significant difference between these results: Chi-Square $(\mathrm{df}=1)$ $=17.23, p=.000$. At baseline, $1 \%$ of charts had a change in medications belonging to the same drug classes. At the two week follow-up, $0 \%$, and at the six week follow-up, $0 \%$ had documentation of a medication change for medications belonging to the same drug class. ChiSquare analysis indicated no significance difference in these results. The number of new or dose-adjusted medications for chronic conditions at baseline was 1.3, at two week follow-up 1.18, and at six week follow-up 1.22. There was no difference between these results.

Finally, the "Reviewed" medications box on the EHR was checked for $45 \%$ of reviewed charts at baseline, $83 \%$ at two week follow-up, and $93 \%$ at six week follow-up. Chi-Square indicated a significant difference in these results: Chi-Square $(\mathrm{df}=2)=66.12, \mathrm{p}=.000$. Telephone audit data indicated that at baseline, $20 \%$ of patients reported being reminded to bring their medications or a list of their medications to their clinic visit, in comparison with $100 \%$ of patients at the six week post-implementation telephone audit: Chi-Square $(\mathrm{df}=1)=20.00, \mathrm{p}=$ .000 . Only $27 \%$ of patients reported brining their medications or a medication list to their appointment at the baseline telephone survey, in comparison to $100 \%$ of patients at the postimplementation phone survey: Chi-Square $(\mathrm{df}=1)=17.37, \mathrm{p}=.000$. Sixty percent of patients reported a member of the healthcare team reconciling their medications in the EHR at the clinic on the baseline telephone survey. At the follow-up survey, $100 \%$ reported a healthcare team member reconciling their medications at the visit: Chi-Square $(\mathrm{df}=1),=7.5, \mathrm{p}=.006$. There was a significant increase in all three reported reconciliation behaviors at the postimplementation telephone survey. It was not possible to ask patients whether they were given a copy of their list of medications at the conclusion of the clinic visit, because an error was discovered in the software program, in that all medications, whether active or ended, were included in this printed list. It was determined that patients would likely be confused by a list that included both current and prior medications. Thus, the practice of providing patients with an 
active medication list on discharge was suspended until this software problem was resolved (refer to Appendix F for the Telephone Survey Tool). Comparisons Results of Telephone Survey Data can be found in Table 1.

Table 1. Comparisons Results of Telephone Survey Data

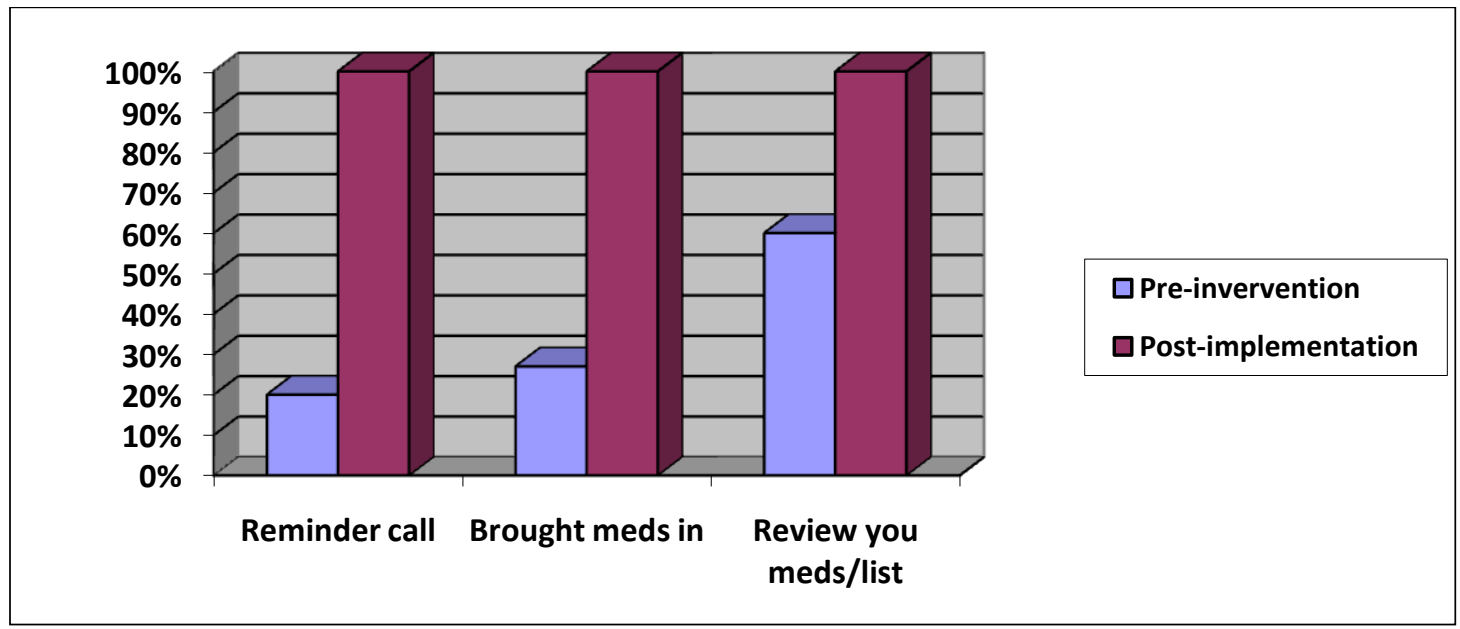

\section{Healthcare Member Survey Results}

All of the healthcare members at the facility (one physician, two APNs, three medical assistances, two receptionists and one office manager) were presented with an open ended survey, consisting of four questions to evaluate positive and negative findings related to the medication reconciliation process changes. Five out of the nine members respond totaling $55.5 \%$. Comments to the first question (Overall, what are your thoughts about the medication reconciliation process, including both phone reminders for patients to bring in their medications or a list of medications, and the reconciliation process during the office visit?) were "Entering all of the patients supplements takes a really long time"; "Just more we have to remember to do"; "It's about time we started do this here"; "This should cut down on potential errors", and; "This is just like at the hospital". Comments to the second question (What problems or barriers have you identified with this process?) were "What if they don't bring a list or their meds?"; "Old people take a lot of time, because of all of their OTCs and supplements"; "This is a mess right now, but I am sure it will get better once we clean up everyone's records", "Its time intensive", and; "They keep updating the system and don't tell us what they have changed, which makes this 
more time intensive". Responses to the third question (What benefits have you found related to the process?) were "No benefits yet"; "Nothing"; "Patients actually like that we are doing this"; "Should help with EMR incentives", and; "This takes more time than the hospital reconciliation did". The final question, (Is there anything that you would suggest to improve this process?) brought the following comments "Should have taught us this with the new system stuff"; I wish we would have started this before we used the "Hide Medications" option" ; "No, it is just going to take time to get use to"; No, it appears to be based on the last standards", and; "No, I have been doing this to the best of my abilities along, but this will make it easier since the patients will be bring in all of their OTCs, supplements, and meds". 


\section{Chapter Five: Conclusion}

\section{Discussion}

Evidence supporting that the implementation of a medication reconciliation practice change at this urban primary care facility was effective is provided through the analysis of data. There was a significant increase in the number of OTCs, vitamins, herbals and home remedies listed on the electronic medication record and also a significant increase in the number of new OTCs, vitamins, herbals and home remedies listed in the record. These data were rarely being gathered pre-practice change, as evidenced by the mean number of OTCs, vitamins, herbals and home remedies at .33. Additional evidence of adoption of the medication reconciliation practice change includes a significant decrease in the number of active medications listed past completion date. Team members had to review the medication lists in order to identify and remove nonactive medications from the lists. Telephone survey data also supported adoption of the practice change with patient reports of $100 \%$ compliance with the healthcare team members' behaviors of instructing the patients to bring medications, OTCS, vitamins, herbals and home remedies or a list to the clinic visit, and reconciling medicines with the patients list at the visit. Postimplementation results represent a significant increase from pre-practice change data.

Additional data supporting the healthcare teams' adoption of the new medication reconciliation process was gathered during week six post-implementation audit, in effort to capture patients who had a previous clinic encounter after the new process was implemented but prior to their encounter during the final data collection date. It was found that a total of 120 OTCs, vitamins, herbals and home remedies had been added to the audited records by the team members after the practice implantation date, but prior to final record audit.

There was a significant difference in the number of medications listed in the electronic medication records between the three audits, with both post-implementation audits being lower. The differences found between the audits demonstrate adoption of the practice change of entering "Stop Dates" for medications that the patients were not taking. A combined total number of 670 medications with "Stop Date" entered in the records provide additional support that the healthcare members were reconciling the medication list. Successful adoption of the practice change relating to entering "Stop Date" for medications no longer active is also 
evidenced by a significant decrease in the number of active acute medications listed past completion date.

Questionnaire results from the participating team members were split. 50\% of the team reported positive thoughts towards the medication reconciliation process. Barriers identified with the process change revolved around the increased time needed to perform the reconciliation process, while benefits relating to the process were perceived by the members as a way of assisting the facility in meeting the new governmental standards for the primary care environment. Suggestions for improvements in the reconciliation process were primarily directed towards the lack of education provided by the vendor with the implementation of the new system.

The findings of this practice change are consistent with those of a systematic review performed by Bayoumi and colleagues (2009) investigating the differences between the patients' and the healthcare providers' medication lists at baseline and after performing the reconciliation practice change. The review demonstrated a decrease from $88.5 \%$ at baseline to $49.1 \%$ post intervention and the medication lists with discrepancies decreased from $88.9 \%$ at baseline to $66 \%$ post intervention ( $\mathrm{p}=0.005$ ), which was statistically significant (Bayoumi et al., 2009). Additionally, a poster abstract by Webb et al., 2010 identified that physicians achieved 76 to $80 \%$ reconciliation of medications after a practice change that focus on medication reconciliation (Webb et al., 2010).

Leonhardt and colleagues conducted a large quasi-experimental study to determine the effects of a community based education program focusing on encouraging patients and healthcare providers to develop a partnership to improve the accuracy of the provider's medication list. They found the increased rate of medication list accuracy at the intervention sites as compared to the control sites from baseline to post intervention $(p=0.034)$. This published study provides additional evidence to support the importance of performing a medication reconciliation process in primary care environment as found in this project.

\section{Project Objective Outcomes}

For this project there were three main objectives. Data related to these three objectives demonstrated significant findings and meeting of the set goals. The telephone survey data indicated $100 \%$ compliance with the first objective (reminding the patients to bring in all of their 
pharmacology agents with them) after implementation of the practice change as compared to $20 \%$ at baseline. Staff compliance with the second objective (demonstrated medication reconciliation) was measured both through the telephone survey and the EHR audits. Telephone survey data indicated $100 \%$ compliance and there was a significant decrease in medications listed post completion date and in total medication numbers. Audits of the electronic medication records also demonstrated a significant increase in the number of OTCs, vitamins, herbals and home remedies listed, and the new OTCs, vitamins, herbals and home remedies and 93\% compliance with checking the "Reviewed" box. These findings represent a significant increase from the pre-practice change data. The third object (entering the patient's medications OTCs, vitamins, herbal and home remedies in the EHR) was also measured both through EHR audits and telephone survey. There was a significant increase in the number of OTCs, vitamins, herbals and home remedies, listed on the electronic medication record and also a significant increase in the number of new OTCs, vitamins, herbals and home remedies listed in the record. Telephone survey data also supported adoption of the practice change with patient reports of $100 \%$ compliance with the healthcare team members' behaviors of reconciling the patient's medications.

\section{Limitations}

The sample population for this practice change being one clinic in urban Ohio limits is generalizability of findings. However, it is possible that this practice change could be replicated in other clinic settings to increase generalizability. The lack of previous established standards for the medication reconciliation process, and the lack of published statistical data made it difficult to draw conclusions relating to the primary care at the practice level and national level.

Vendor support was identified as a limitation (system capabilities differ between EHR vendors, which also limits generalizability to other clinics). Prior to the collection of the baseline data, the system had been updated, which made the printed version of the medication record unacceptable to present to patienst at the end of their encounter. The system included the medications with "Stop Date", prescribed medications, entered medications, renewed medications, and filled medications, which meant one medication could appear at least three times on the patient's medication record. Therefore, it was the decision of the Physician/owner not to provide the patients' with a printed version. The vendor was contacted with no resolution 
for the problems identified within the system. The software system was updated again prior to gathering the final record review data. Findings from the record review indicated that the vendor had corrected the showing of prescribed medications, entered medications, renewed medications, and filled medications on the active electronic medication record, but medications that had a "Stop Date" continued to appear through the record review.

The data collection process had a potential for bias and error. Data were collected and analyzed by the PI. The interpretation of a chronic diagnosis, assessment of acute medications, and presences of two active medications from the same drug class interpretations were at the discretion of the PI. However, the PI used resources available within the software system and drug references to make these determinations. This study did not account for whether the reminder phone calls were left on an answering machine, with a significant other, or were communicated directly to the patient. Therefore, variability and inconsistency in the process may have occurred.

\section{Additional Findings}

The mean patient age identified of all three audits was 61 to 63 years of age. The older population has a greater risk of experiencing an adverse medication event because of multiple providers, numerous medications, and increased number of chronic health conditions. This study found that using a certified EHR together with proactive steps in medication reconciliation can decrease the risk of adverse medication events. In addition, this study identified that the aging population uses higher numbers of OTCs, vitamins, herbals and home remedies: Pearson's correlation $.25, \mathrm{p}=.000$, and if not documented, these products can put this population at a higher risk of an adverse medication event impacting health outcomes. A study by Wet and colleagues in 2009 , found that the number of medication related errors increased with age greater than 65 years (59\%) and particularly with patients 75 years and older (36\%), due to the increased number of prescribed medications (Wet \& Bowie, 2009).

\section{Future Recommendations}

All primary care providers should be working towards medication reconciliation during all patient encounters. With the passing of the Patient Affordable Health Care Act, the final ruling on the Meaningful Use Objectives and Associated Measures for the Electronic Health Record Inventive Programs, and the implementation of the PQRI measures, primary care 
facilities will be forced to place a greater focus on patient safety measures and outcomes. These newly adopted standards will prompt primary care clinics to change their current medication practices and consistently implement medication reconciliation practices, with the goal of decreasing the risk for making a medication error.

In today's fast paced health care environment, healthcare providers need to have quick access to current medical data to support the of goal providing their patients with holistic, safe, cost effective, high quality care, in a timely manner. Medication errors occur in both general practice and hospital environments and have a direct impact on patients' safety and health outcomes. Adoption of an electronic medication reconciliation process can reduce medication errors, aid in preventing drug-drug interaction, disease-drug interactions, and OTCs, vitamins, herbals and home remedies' interactions with medications and chronic diseases, while enhancing patient outcomes relating to the prescribing practices in primary care.

It is the recommendation of this PI that the medication reconciliation process be reevaluated in six months and annually hereafter to maintain the standard of care and to use as benchmarking criteria for this primary care practice. Development of a policy for medication reconciliation at this facility is also a recommendation of the PI to ensure that any new members to the healthcare team would be informed of the practice standards. Due to the organizational structure at this facility, these recommendations fall under the role of the office manager; however this PI will be available to assist in the development, implementation, and evaluation of these recommendations.

\section{Relation of Practice Change Project to Personal Goals}

It is a goal of mine to establish a nurse run Advanced Practice Clinic in urban Ohio. My previous roles in the nursing profession along with my advanced education and training as an adult Clinical Nurse Specialist has proven invaluable to me through this practice change. Twenty plus years in the hospital environment, with the last 12 years being in management, provided me with the insight of how in implement and evaluate change, plus provided me with a firsthand understanding of risk management strategies, total quality improvement process, and JCAHO standards. The years I spent as a clinical nursing instructor assisted me with developing appropriate teaching strategies for both formal and informal education efforts. Through this process I was also able to gain a higher level of knowledge with electronic health records, PQRI, 
and the Meaningful Use criteria, which are all necessary to understand prior to establishing a nurse run Advanced Practice Clinic. 


\section{References}

Bates, D. W., \& Gawande, A. A., (2003). Improving safety with information technology. The New England Journal of Medicine, 348(25), 2526-2534.

Bayoumi, I., Howard, M., Holbrook, A. M., \& Schabort, I. ( 2009). Interventions to improve Medication reconciliation in primary care. The Annals of Pharmacotherapy, 43(10), 1167-1675.

Bell, D. S., \& Friedman, M. A., (2005). E-prescribing and the medicare modernization act of 2003. Health Affairs, 24(5), 1159-1169.

Centers for Medicare and Medicaid Services, E-Prescribing and the Prescription Drug Program; Proposed Rule, (2005). Federal Register, 70(214), 67568-67595.

Centers for Medicare and Medicaid Services (CMS); Electronic Prescribing (eRX) Incentive Program. (2010). Retrieved on February 27, 2011 from http://www.cms.gov/ERXincentive/

Chaudhry, B., Wang, J., Wu, S., Maglione, M., Mojica, W., Roth, E.,... Shekelle, P.G. (2006). Systematic review: Impact of health information technology on quality, efficiency, and cost of medical care. Annuals of Internal Medicine, 14(10), 742-752.

Department of Health and Human Services, Centers for Medicare and Medicaid Services Medicare and Medicaid Programs; Electronic Health Record Incentive Program; Final Rule. (2010). Federal Register, 75(144), 44314-44588.

Elder, N.C., \& Dovey, S. M. (2002). Classification of medical errors and preventable adverse Events in primary care: A synthesis of the literature. The Journal of Family Practice, 51 (11), 927-932.

Elder, N. C., Vonder Meulen, M., \& Cassedy, A. (2004). The identification of medical errors by family physicians during outpatient visits. Annals of Family Medicine, 2(2), 125-129.

Geraci, E. P. (1997). Computers in home care application of change theory. Computers In Nursing, 15(4), 199-203.

Hesselgreaves, H., Lough, M., \& Power, A. (2009). The perceptions of reception staff in general practice about the factors influencing specific medication errors. Education for Primary Care, 20, 21-27.

Holman, P, \& Devane, T. (2000). The changing nature of change: Whole system methods for 
shaping the future, 1-8. Retrieved October 29, 2009, from

http://www.opencirclecompany.com/IAF\%20paper.htm.

Institute of Medicine [IOM]. 1999. To err is human: Building a safer health system. Retrieved

March 15, 2010 from www.nap.edu/html/to_err_is_human/reportbrief.pdf

Jones, S. \& Moss, J. (2006). Computerized provider order entry strategies for successful Implementation. The Journal of Nursing Administration, 36(3), 136-139.

Larrabee, J. H. (2009). Nurse to nurse evidence-based practice: Expert interventions. New York: McGraw-Hill.

Leonhardt, K. K., Pagel, P., Bonin, D., Moberg, D. P., Dvorak, M. L., \& Hatlie, M. J. (2008).

Creating and accurate medication list in the outpatient setting through a patient-centered Approach. Retreived July 27, 2010 from

www.ahrg.gov/downloads/pub/.../vol3/advances-leonhardt_35.pdf

Lippitt, R., Waston, J., \& Westley, B. (1958). The dynamics of planned change a comparative study of principles and techniques. New York, Chicago, San Francisco, Atlanta: Harcourt, Brace \& World, Inc.

The Joint Commission. (2008). Joint commission standard. Retrieved March 18, 2010, and July 28, 2010 from www.jiontcommission.org

The National Coordinating Council for Mediation Error Reporting and Prevention [NCC MERP]: The first ten years, "Defining the problem and developing solutions". 2005. Retrieved March 5, 2010 from www.nccmerp.org

Rubin, G., George, A., Chinn, D. J., \& Richardson, C. (2010). Errors in general practice: development of an error classification and pilot study of a method for detecting errors. Quality and Safety in Health Care, 12, 443-447.

Santell, J. P., Hicks, R. W., McMeekin, J. \& Cousins, D. D. (2003). Medication errors: Experience of the United States pharmacopeia (USP) MEDMARX reporting system. The Journal of Clinical Pharmacology, 43, 760-767.

Scottish Intercollegiate Guidelines Network (2007). Critical appraisal: Notes and checklist. Retrieved September 2, 2009, from http://www.sign.ac.uk/methodology/checklists.html

Tam, K. W., Kwok, K. H., Fan, Y. M., Tsui, K. B., Ng, K. K., Ho, K. Y.,...Lau, C. M. 
(2008). Detection and prevention of medication misadventures in general practice. International Journal for Quality in Health Care, 20(3), 192-199.

Thomsen, L. A., Winterstein, A. G., Sondergaard, B., Haughbolle, L.S., \& Melander, A. (2007) Systematic review of the incidence and characteristics of preventable adverse drug events in ambulatory care. The Annals of Pharmacotherapy, 41(9), 1411-1426.

Velo, G. P., \& Minuz, P. (2009) Medication errors: prescribing faults and prescription errors. The British Journal of Clinical Pharmacology, 67(6), 624-628.

Webb, J., Rittenberg, L, Makone, G. Dunham, D. Baker, D. W., Wolf, M. S. (2010). A medication reconciliation and education strategy $(\mathrm{NuMed})$ for ambulatory care. Poster Presentation at the Health Literacy Annual Research Conference October 18, 2010 in Bethesda, MD

Wet, C. D., \& Bowie, P. (2009). The preliminary development and testing of a global trigger tool to detect error and patient harm in primary-care records. Postgraduate Medical Journal, 85, 176-180. 
Appendix A Theoretical Framework Overview

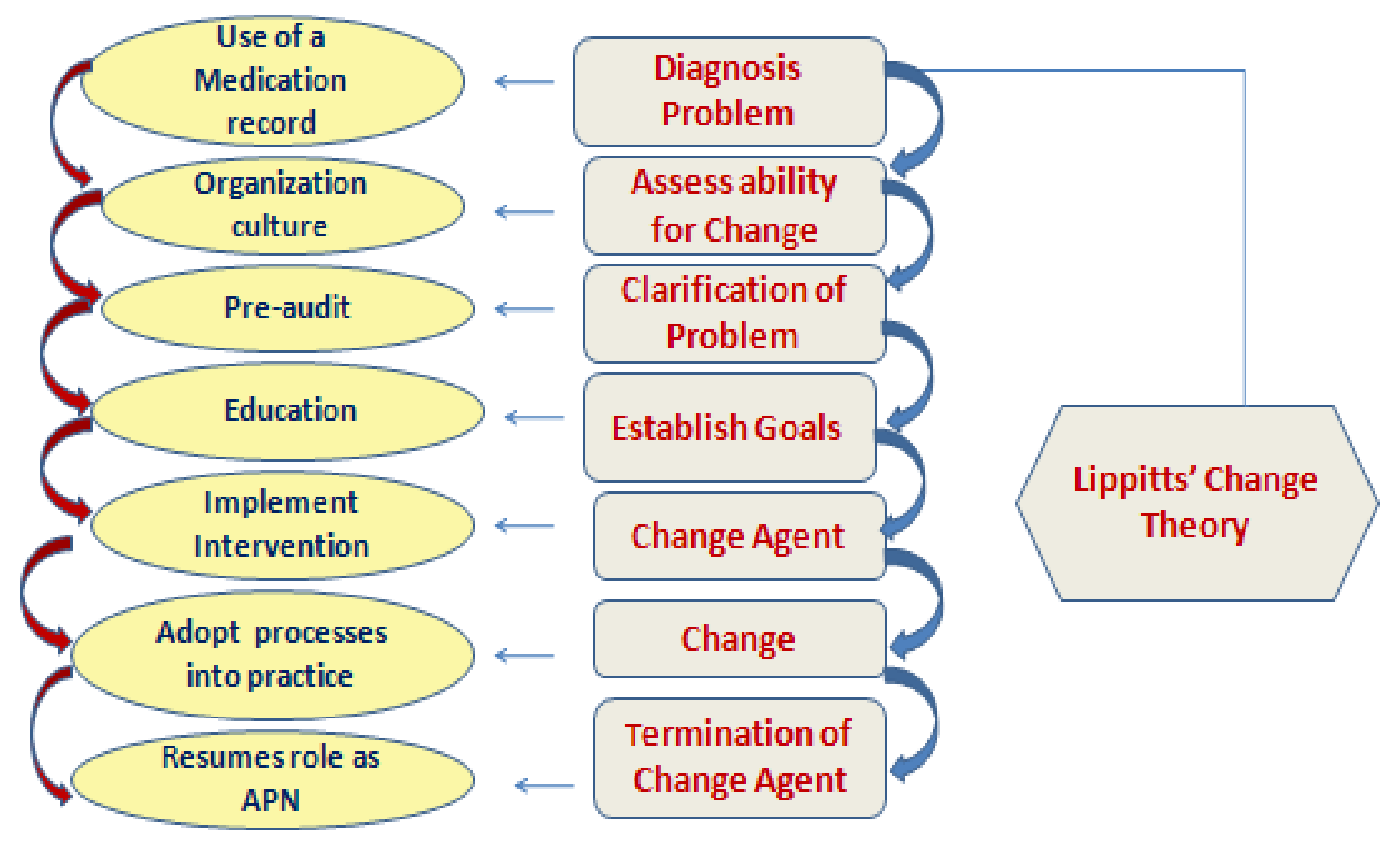




\section{Appendix B Signed Agreement}

James E. Richardson, M.D.

Mansfield Internal Medicine, Inc.

370 Cline Avenue, Suite C6

Mansfield, Ohio 44907

419-775-0042

June 9,2010

DNP Capstone Project Site Approval

To: Health Sciences Graduate Programs Office at West Virginia University

From: Laura L Danals MSN, ACNS-BC, Doctor of Nursing Practice Student

Dr. J. Richardson has agreed to allow Laura L. Danals MSN, ACNS-BC, DNP student to complete her Capstone Project entitled: Evaluation of a Medication Progress Record at the Mansfield Internal Medicine Practice including the ability to publish the results of this project.
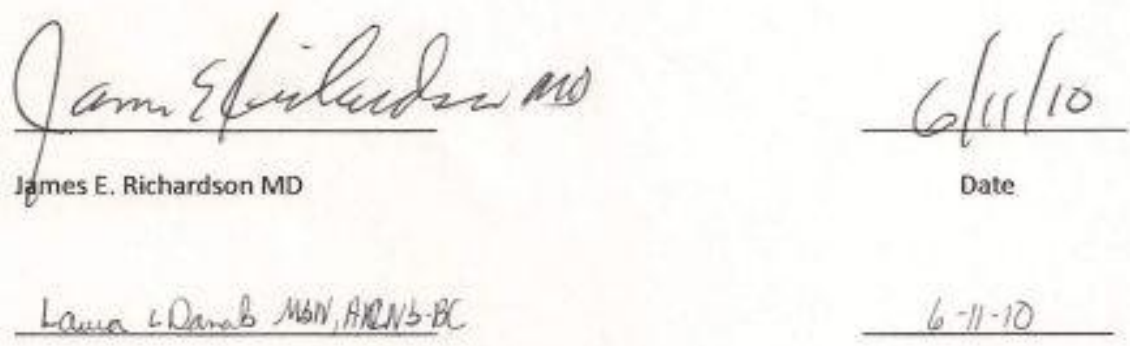

$\underline{L a} \quad+\underline{b \cdot B C}$

Date 
Appendix C Educational Handouts

\section{Medication Reconciliation Education}

\section{Purpose Statement for the Medication Reconciliation Process}

Mansfield Internal Medicine, Incorporated will have a process for obtaining and documenting a complete list of the patient's current medications, over-the-counter (OTCs), vitamins, herbals and home remedies. This process will start with instructing every patient at all visits to bring in or supply a complete list of all their medications, OTCs, vitamins, herbals and home remedies they are currently taking and using during the reminder phone call and includes a reconciliation of the patient's medications, vitamins, OTCs, herbals and home remedies against the provider's medication record during the encounter and to present the patient with a printed copy of their medications at departure.

\section{Purpose}

The purpose statement for the Medication Reconciliation Process is: to reduce the number of medication mistakes.

\section{Procedure}

Medication Reconciliation activities for each encounter will include all of the following:

A. Creation of a complete and accurate medication list in the patient's electronic health record (EHR). This will include all of the patients' pharmacological agents in current use including prescription medications, OTCs, vitamins, herbals and home remedies.

B. Identification of inaccuracies and clarification of the medication list.

C. Reconciliation of the medication record to determine those medications to initiate, continue, discontinue, or change.

Medication Reconciliation will be performed at every patient encounter

A. An appointment reminder phone call will begin the process by instructing every patient at all visits to bring in or supply a complete list of all their medications, OTCs, vitamins, herbals and home remedies which they are currently taking and using. This is to be initiated by the receptionist or other designated healthcare team member at every visit. 
B. Encounter- Medication Reconciliation will begin when the patient presents for an office visit. This is to be initiated by the medical assistants or other designated healthcare team member at every patient visit.

1. All of the patient's pharmacological agents/list will be obtained from the patient at the beginning of the visit and entered into the EHR.

2. The patient's pharmacological agents or list will be compared to the provider's current list making changes as necessary and entering "Stop Date".

3. The providers will verify that the reconciliation occurred by assessing the patient's electronic medication record for listing of OTCs, vitamins, herbals and home remedies, "Stop Date" for all acute medications past completion date, only one active medication from the same drug class, and reviewing all potential interactions within the patient's medication record by clicking on the "Reviewed" box in the patient's electronic medication section at the end of each encounter to capture any medication changes and new medications prescribed.

4. If this is not the patient's first encounter, the patient's pharmacological agents or list will be obtained and reconciled for any changes to the list at each encounter.

a. If a medication is no longer active, or a "Stop Date" is not present, the healthcare member will enter the date stopped in the "Stop Date" box by clicking on the calendar to the right of the box and selecting the date. If the patient is unable to recall the stop date, than the encounter date will be entered.

b. If the dosages or frequency has been adjusted on a medication, then the healthcare team member will stop the medication currently listed in the EHR by entering the dated in the "Stop Date" box, and re-enter the medication with the new dosage or frequency.

c. All active acute pharmacological agents listed as active past there completing date need to be stopped by entering the date in the "Stop Date" box.

d. All new pharmacological agents will be entered into the patient's electronic medication record. 
e. Once the medications have been entered, the provider will verify the reconciliation by clicking on the "Reviewed" in the patient's electronic medication section at the end of the encounter.

C. Patient encounter- the Medication Reconciliation will be reviewed by the provider during each patient encounter. Verification that the medication reconciliation process has been completed will be indicated by the provider clicking on the "Reviewed" box in the patient's medication record at the end of the encounter. Evidence that the reconciliation process has occurred will be indicated up by visualizing "Reviewed patient's new medication history" located in the top left hand corner directly under Medication History.

D. Completion of encounter- the Medication Reconciliation will be printed by the provider at the end of each patient encounter unless they have a printed list and no changes have been made to that list. The receptionist will present the printed medication list to the patient during the departure. 


\title{
Practice Medication Safety
}

\author{
Medications or list with you?
}

Every prescribed drug, over-the-counter

drug, vitamin, herbal, and home

remedy you are taking or using is

listed?

Doctors need to know everything you are taking or using

Safe medication practices saves lives 
Appendix E Medication Record Data Collection Form

\begin{tabular}{|c|c|c|c|c|c|c|c|c|c|c|c|}
\hline 1 & 2 & 3 & 4 & 5 & 6 & 7 & 8 & 9 & 10 & 11 & 13 \\
\hline $\begin{array}{l}\text { Gender } \\
(\mathrm{M} / \mathrm{F})\end{array}$ & Age & $\begin{array}{l}\text { Number } \\
\text { of } \\
\text { chronic } \\
\text { diagnosis } \\
\text { listed }\end{array}$ & $\begin{array}{l}\text { Number } \\
\text { of meds } \\
\text { on Chart }\end{array}$ & $\begin{array}{c}\text { Number } \\
\text { OTC,vits, } \\
\text { herbal, } \\
\text { home } \\
\text { remedies } \\
\text { on the } \\
\text { chart }\end{array}$ & $\begin{array}{c}\text { Number } \\
\text { of acute } \\
\text { meds } \\
\text { listed } \\
\text { past } \\
\text { comple- } \\
\text { tion date }\end{array}$ & $\begin{array}{c}\text { Presence } \\
\text { of } 2 \text { active } \\
\text { meds } \\
\text { within } \\
\text { same drug } \\
\text { class } \\
(\mathrm{Y}=1 / \\
\mathrm{N}=2) \\
\end{array}$ & $\begin{array}{c}\text { Number } \\
\text { of new or } \\
\text { dose } \\
\text { adjust- } \\
\text { ments of } \\
\text { chronic } \\
\text { meds }\end{array}$ & $\begin{array}{l}\text { Number } \\
\text { of new } \\
\text { OTC, vits, } \\
\text { herbal, } \\
\text { home } \\
\text { remedies } \\
\text { on the } \\
\text { chart } \\
\end{array}$ & $\begin{array}{c}\text { Number } \\
\text { of new } \\
\text { acute } \\
\text { meds }\end{array}$ & $\begin{array}{c}\text { Change } \\
\text { in meds } \\
\mathrm{d} / \mathrm{t} \text { same } \\
\text { drug } \\
\text { class } \\
(\mathrm{Y}=1 / \\
\mathrm{N}=2)\end{array}$ & $\begin{array}{c}\text { Review } \\
\text { box } \\
\text { checked } \\
(\mathrm{Y}=1 / \\
\mathrm{N}=2 / \\
\mathrm{NA}=3)\end{array}$ \\
\hline & & & & & & & & & & & \\
\hline & & & & & & & & & & & \\
\hline & & & & & & & & & & & \\
\hline & & & & & & & & & & & \\
\hline & & & & & & & & & & & \\
\hline & & & & & & & & & & & \\
\hline & & & & & & & & & & & \\
\hline & & & & & & & & & & & \\
\hline & & & & & & & & & & & \\
\hline & & & & & & & & & & & \\
\hline & & & & & & & & & & & \\
\hline & & & & & & & & & & & \\
\hline & & & & & & & & & & & \\
\hline & & & & & & & & & & & \\
\hline
\end{tabular}




\section{Appendix F Telephone Survey Data Collection Tool}

\begin{tabular}{|c|c|c|c|c|}
\hline $\begin{array}{l}\text { Review } \\
\text { Number }\end{array}$ & $\begin{array}{l}\text { Where you instructed } \\
\text { during your } \\
\text { appointment reminder } \\
\text { call to bring in all of } \\
\text { your meds/list, } \\
\text { including OTC, vits, } \\
\text { herbal, home remedies } \\
\text { you are currently } \\
\text { taking/using ( } \mathrm{Y}=1 / \\
\mathrm{N}=2 \text { ) }\end{array}$ & $\begin{array}{l}\text { Did you bring in all } \\
\text { of your meds/list, } \\
\text { including OTC, } \\
\text { vits, herbal, home } \\
\text { remedies you are } \\
\text { currently } \\
\text { taking/using ( } \mathrm{Y}=1 / \\
\mathrm{N}=2)\end{array}$ & $\begin{array}{l}\text { Did one of the } \\
\text { healthcare } \\
\text { team members } \\
\text { review your } \\
\text { meds/list, } \\
\text { including } \\
\text { OTC, vits, } \\
\text { herbal, home } \\
\text { remedies with } \\
\text { you, making } \\
\text { any needed } \\
\text { changes in the } \\
\text { computer } \\
(\mathrm{Y}=1 / \mathrm{N}=2)\end{array}$ & $\begin{array}{l}\text { Where you } \\
\text { given a } \\
\text { printed med } \\
\text { list upon your } \\
\text { departure } \\
(\mathrm{Y}=1 / \mathrm{N}=2)\end{array}$ \\
\hline 1 & & & & \\
\hline 2 & & & & \\
\hline 3 & & & & \\
\hline 4 & & & & \\
\hline 5 & & & & \\
\hline 6 & & & & \\
\hline 7 & & & & \\
\hline 8 & & & & \\
\hline 9 & & & & \\
\hline 10 & & & & \\
\hline 11 & & & & \\
\hline 12 & & & & \\
\hline
\end{tabular}


Appendix G Healthcare Member Evaluation Questionnaire

1. Overall, what are your thoughts about the medication reconciliation process, including both phone reminders for patients to bring in their medications or a list of medications, and the reconciliation during the office visit (respondent write in response)?

2. What problems or barriers have you identified with this process?

3. What benefits have you found related to the process?

4. Is there anything that you would suggest to improve this process?

All responses will be kept confidential and are for the purpose of improving medication safety within this facility.

Thank you for your time and honesty in your responses. 
May I please speak to ? My name is Laura Danals and I am call from Mansfield Internal Medicine (Dr. Richardson's practice). I am a doctor of nursing student at the University of West Virginia, and I am gathering information on the medication reconciliation practices at Mansfield Internal Medicine. Involvement in this survey is entirely voluntary, and you may decline to answer any of the interview questions you do not wish to answer and terminate the interview at any time. All information you provide will be considered confidential. The survey will take about five minutes and consist of four yes or no questions.

This study has been reviewed and received ethics clearance through the institutional review board (IRB) at West Virginia University (WVU). The data collected will be used to evaluate the goal of this project, which is to evaluate the use of the medication reconciliation process in the EMR at Mansfield Internal Medicine and improve the accuracy of medication records contained in the EMR. Individual respondents are not identified by name. If you have any questions regarding this study, or would like additional information please feel free to contact Laura Danals at 419-775-0042 or WVUs IRB at 304-293-4245. 